ceutical preparations from the class of fraudulent nostrums described is a most difficult undertaking. This perplexing problem forced itself from year to year on the attention of the board of trustees in the effort of the board to keep the advertising pages of the Journal free from unethical advertisements. In order to have thorough protection and to make no unjust discrimination, the board has established the council on pharmacy and chemistry to make the necessary investigations. The council is composed of pharmacists and chemists of national and international reputation. It will be the aim of the council to publish in book form, a list of the preparations which are not officinal, yet which conform to the proper ethical standard. The work of the council will be similar to that of the Committee on Revision of the United States Pharmacopeia.

The magnitude and importance of this work is such that I desire to direct attention to it here, and to commend it to the members of the association as deserving every possible aid and advancement. It is the only practical way to deliver the profession from one of the greatest curses that ever came on it.

It has been my endeavor on this occasion to outline the plans of the founders of the association, briefly to trace the evolution of those plans throughout half a century of progress, and to recount some of the purposes that invite our active exertions at the present time. From a small body of delegates our association has increased until it is now the largest medical organization in the world. It owns valuable property, has accumulated a considerable fund, and has a large annual income, all of which belongs to, and is subject to the control of, the members who through their delegates select the board of trustees to manage their funds.

The possibilities of the work before us are älmost beyond calculation. In acting as the representative and agent of the 120,000 physicians of the United States, the association is assuming great responsibilities, which will increase from year to year. It will require administrative and executive ability of the highest order to meet these demands; but there is both prophecy and proof in the work already accomplished that men will appear as needed to discharge the supreme duties of a great profession in behalf of science and humanity.

LouISVIIL'́, KY.

Lewis S. McMurTry.'

\section{THE RELATION OF PHYLOGENESIS TO HISTORICAL GEOLOGY.}

Few persons would be so bold as to offer serious objection to the great thesis of evolution, to the theory of common descent or to that of the competitive struggle of individuals and species for existence and its selective results, so ably enunciated by Darwin half a century ago. It is, nevertheless, true that of late years there has been an increasing distrust of the theory of the origin of species by natural selection which he therewith proposed, and which was long universally accepted with even less reserve than the author himself expressed. This distrust is especially felt in endeavoring to apply the latter theory to certain lines of paleontological investigation. ,A number of selected facts are stated at some length on following pages which show abundant reason for regarding that theory unfavorably in such cases. It is there shown that genera, families, orders and classes of animals and plants have, during geological time, usually originated with such comparative rapidity as to make it necessary to infer that species have originated suddenly; that the ratio of progressive development in the different faunal and floral divisions 
has not only not been uniform during geologieal time, but that it has been exceedingly diverse; that those genera, families, orders and classes which have become extinct have, in many cases, declined and perished amid general conditions of physical environment which were evidently quite as favorable to their existence as were those amid which they originated; that certain generic and family forms have survived unchanged through vicissitudes and restrictions of habitation so adverse as to have been again and again apparently more than sufficient for their utter destruction; and that unknown determinate natural causes have acted, sometimes in the destruction, sometimes in the conservation, and sometimes in the extreme differentiation, of typical forms of life, often in seeming independence of environing physical conditions. In making application of those facts it will be shown that some theory of the rapid or sudden origination of species is necessary to harmonize them with the past conditions which they reveal. That the theory of the origin of species by natural selection will not harmonize with those facts will be made sufficiently plain by comparing each of them with the following statement of the chief features of that theory.

That is, that species originate from one another genetically by a process of transformation which requires indefinite time for its accomplishment, and which is, therefore, too slow for actual observation. Such transformation is the result of cumulative repetition, from generation to generation, of small variations such as always prevail in organic forms, until varieties, races, and then species, are produced and the higher groups which they compose are established. Variation is induced and its specific results conserved by physical conditions of environment as a dominant influence and by the struggle for existence under which the comparatively few fittest individuals survive and the infinite number of weaklings, which are born of individuals of all species, perish. Species, therefore, have no definite entity, even when fully developed, but are constantly changing toward the production of other species.

Three of the assumptions which are made by the advocates of this theory are plainly inconsistent with the facts which are presently to be stated, and they only will be discussed on the present occasion: One of them requires the paramount influence of physical conditions of environment for the origination of species and in the conservation of the higher groups which they constitute. One demands immeasurable time for the production of a single species, and consequently the lapse of illimitable time since the beginning of life upon the earth. The other implies that species have no existence as such, but that all of them are in a state of constant change. These assumptions will be separately considered further on.

The accompanying diagram is presented for the purpose of illustrating some of the principal facts that are mentioned in the statements which are to follow.

The horizontal spaces of the diagram represent the respective ages of geological history as they have been determined by the presence and characters of the fossil remains found in their strata. The perpendicular lines represent the principal great groups of animals and plants whose remains are found there. Thus the five lines under $A$ represent the five subkingdoms of marine invertebrates, the Protozoa, Cœlenterata, Annuloida, Annulosa and Mollusca. The left-hand line under $B$ represents the non-marine, and the righthand line the land, invertebrates. $C$, fishes; left-hand line, selachians; right, 
teleosts. $D$, batrachians and reptiles; lefthand line batrachians; right, dinosaurs; middle, all other reptiles. $E$, birds, single line. $F$, mammals ; left-hand line, non-placental; right, placental. $G$, land plants; right-hand line dicotyledons and palms; left, all other kinds. The dotted portion of a part of those lines indicates some doubt as to the epoch in which the kind represented by such a line was introduced.

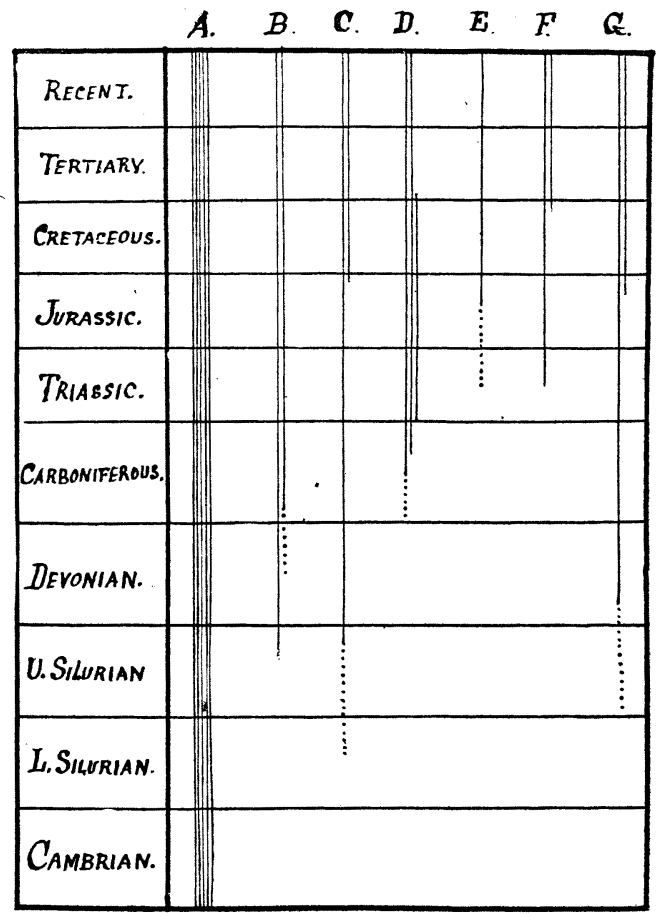

DIAGRAM SHOWING TIME-RANGE OF CHIEF-KINDS OF ANIMALS AND PLANTS.

$A$, marine invertebrates; $B$, non-marine and land invertebrates; $C$, fishes; $D$, batrachians and reptiles; $E$, birds; $F$, mammals; $G$, land plants.

This diagram thus represents the earliest known epoch of existence of each of the principal kinds of animals and plants, and their continued existence through subsequent geological time. It is a significant fact that, so far as can be judged by their fossil remains, every kind represented on the diagram began its existence with a comparatively high grade of its own types of organization. The instances which will be presented in support of the propositions that were stated in the opening paragraph of this article will necessarily be disconnected in their statement because, in an article like this, there is only opportunity to consider some of the more striking facts selected from a multitude.

The strata of lower Cambrian age contain remains of the earliest forms of life that are known to have existed upon the earth. $^{1}$ Large series of rocks, more or less distinctly stratified like those of Cambrian age are, in some regions, found underlying the latter; but no classifiable fossil remains have been found in them, and little evidence has been discovered that life existed before the Cambrian age. The fossil remains which are found in the Cambrian strata pertain to all five of the invertebrate subkingdoms, the vertebrata only being absent; and remains belonging to each of those five subkingdoms are found in all, even the lowermost, of the Cambrian formations. Representatives of those five subkingdoms have continued to exist through all the subsequent ages to the present time in ever-varying forms within the limited scope of their faunal rank, but those representatives were evidently connected by continuous genetic lines, as is represented un$\operatorname{der} A$ on the diagram. So little change is found to have occurred in the general organic rank of those subkingdoms that one may justly assume nearly as high grade for. the earliest as for the latest members. Those earliest known animal types either originated with comparative suddenness and then continued through subsequent

${ }^{1}$ For the present occasion $I$ treat the reported fossiliferous Algonkian rocks of Utah and Montana as not older than the lower Cambrian; but even if they are really older, that fact will not affect the validity of my argument, except to enforce it. 
time with their chief characteristics unchanged, or they originated in some far distant age of pre-Cambrian time and reached their now known earliest stage of evolution quite as slowly as they have changed since they reached that stage. Aside from the absence of evidence in favor of the latter supposition, it is an improbable one in view of that extremely slow increase of faunal rank in those subkingdoms which has just been mentioned. To indicate that slow increase of faunal rank we may postulate a pair of chronological lines extending from the Cambrian age to the present time as the two sides of an evolutional angle of parallax. The divergence of such a pair of lines would be so exceedingly small that the apex, which would represent the beginning of life, will be carried back into the abyss of time to a point inconceivably remote. It, therefore, seems necessary to conclude that the earliest Cambrian faunas had a comparatively sudden origin, notwithstanding the fact that their development diverged so slowly through subsequent time.

A case partly similar to the one just stated, but which is of narrower faunal scope and shorter. chronological range, is presented by the Unionidæ, the oldest certainly known fossil remains of which family are found in Triassic strata. ${ }^{2}$ Similar remains are also found in successive formations to the present time, living representatives of the family being abundant in the lakes and rivers of the world. The genus Unio, the typical member of that generically small family, is thus known to have existed continuously and unchanged during all that stretch of time in which all the mammals, all the birds, all the teleost fishes, and all the exogenous plants of the

2 Those Devonian shells which were referred by Vanuxem to Anodonta, the several species of the Naiadites of Dawson, and other paleozoic shells, I do not now regard as belonging to the Unionidæ. earth were introduced, and in which the dinosaurs culminated and became extinct. These earliest representatives of the Unionidæ are fully characteristic of the family, but no certain trace of any previously existing member of it has been found in any older strata. It seems necessary to assume that this family, by its typical genus, was suddenly introduced at that early period, and that it has remained without material change through all the subsequent ages.

One may suggest that the marine invertebrates, which are represented by the five lines under $A$ on the diagram, have preserved their faunal integrity through all the geological ages because they had a continuous congenial marine habitat. But the fresh-water invertebrates have survived with quite. as little change without such obvious advantages. For example, the Unionidæ were from age to age subject to shifting and adverse conditions resulting from the changing relations of lands and waters, and from the restriction and isolation to which all fresh waters are subjected by intervening land. Their habitable range was also restricted by the marine waters into which their congenial fresh waters flowed. If physical conditions of environment were the dominant factors in phylogenetic differentiation we should expect that these and other faunal groups of fossil fresh-water mollusca would have become widely and profusely differentiated. As a matter of fact, however, those diverse and frequently changing conditions did not result in great differentiation of fresh water faunas in general, a fact which is of importance in this connection. On the contrary, all fresh-water faunas are notably much less diversified than are marine faunas; and fresh-water mollusca especially have retained their primitive types through long geological ages under the 
vicissitudes just mentioned. Moreover, the most ancient types found among living fishes are denizens of fresh, and not of marine, waters. This fact indicates that the genetic lines of those ichthyic types also were not wholly broken by such shifting physical conditions, and that the genetic lines of their marine congeners were not preserved by having less restricted and more uniform conditions of environment.

The chief object of the immediately preceding paragraph is to show the strong contrast between the conditions which have attended the genetic descent of fresh-water. and marine faunas respectively. By way of explanation it is proper to say, however, that the only manner in which unbroken genetic lines of fresh-water faunas could have been preserved through the geological ages to the present time is through unbroken fresh water conditions. Such conditions could have been preserved only by the persistence of rivers in their established channels, so that at least some portions of them, together with their faunas, have escaped destruction by all subsequent elevations and depressions of land surface. ${ }^{3}$

During the Triassic and Jurassic periods the genus Unio was the only known representative of its family, and it has always been the leading genus of that family since those periods. This fact shows that, contrary to a prevailing belief, rare genera are not always disappearing or decadent genera. It is also worthy of remark in this connection that although genera were sometimes so long-lived, the geological record shows that the duration of species was comparatively short. The sudden introduction of the Unionidæ by its leading genus, Unio, without known congeners, and its survival unchanged through all subsequent ages under peculiarly adverse condi-

${ }^{3}$ See my discussion of this subject in Third Annual Report of the U. S. Geological Survey, pp. $479-486$. tions, are all inconsistent with the theory of the origin of species by natural selection. They are also inconsistent with the assumption that the influence of physical conditions of environment has been a constant dominant factor in phylogenetic differentiation, on the one hand, and of conservation of established living forms on the other.

The earliest known remains of the great subclass of dinosaurian reptiles are found in early Triassic strata, and the latest known representatives of that great subclass barely survived the close of the Cretaceous period, as is shown by the presence of their remains in the upper strata of the Laramie formation, associated with animal and plant remains belonging to Tertiary types. The beginning and end of the comparatively short time range for such a large and diversified subclass of dominant and distinctive animals is shown by the right-hand line under. $D$ on the diagram. Those strangely peculiar animals were introduced suddenly, soon existed in multitudes, became dispersed over the earth with great rapidity and, from their beginning, they were the dominant animals of all the continents. They varied in size from that of a rabbit to that which would be equal to several large elephants; and the grade of organization for the whole subclass was as high in the earlier as in the later part of its existence. They were differentiated into flesh eaters and plant eaters and into denizens of land and water respectively. We know absolutely nothing of the genetic origin of those remarkable animals, and no traces of similar animals have been found in any strata older than those' containing their early Triàssic remains. Their world-wide decadence was not delayed by the improving earth-conditions which the mammalia, soon to assume faunal dominion, found abundantly con- 
genial; and the last of their kind perished so utterly at, or immediately after, the close of the Cretaceous period that the earth has since contained no living representative of any of them.

I once tried to account for the sudden disappearance of the dinosaurs by supposing the coalescence of continental areas which they occupied with others upon which powerful Eocene mammals had been separately introduced, assuming that the final destruction of the dinosaurs occurred in the fierce conflicts which would naturally follow. But such a suggestion presupposes the contemporaneous existence, in separate regions, of highly organized and characteristic Mesozoic and Tertiary vertebrate faunas, which one is naturally slow to believe. The occurrence of such continental changes has not been proved, and no paleontological battlefields, with mingled remains of the mighty combatants, have ever been discovered. It seems impossible to conceive of the applicability of the theory of the origin of species by natural selection to any of the chief features of the strange faunal history of the dinosaurs, or to their sudden origination and extinction.

We know little or nothing of the ancestry, or of the genetic succession of the unique, abundant and universally distributed flora of the Carboniferous age. It differed materially in character from that of the flora which preceded it, and it was even more different from all succeeding floras. Its forms were so diverse, and their family characteristics so distinctly defined, that the idea of such a gradual transition from one to another as the theory of their origin by natural selection requires seems to be wholly inadmissible.

The palms and exogenous trees, represented by the right-hand line under $G$ on the diagram, were introduced with appa- rently great suddenness in late Jurassic time, and those earliest known plants of their kinds had essentially the same grade of organization that those kinds now possess, although their subsequent evolution has been comparatively slight as regards floral rank.

Birds, having unmistakably reptilian characters, are known by their remains to have existed in the Jurassic and Cretaceous periods; but remains of the earliest known true birds, such as are referable to any of the living orders, are found in strata of the Eocene Tertiary, and they seem to have originated suddenly in that epoch. These, and all living birds, differ greatly from those older kinds, and no intervening kinds have been discovered. It is true that in this case, as in other similar cases, the paleontological record is far from complete, but the epochs in which the older and later forms, respectively, are known to have existed were apparently separated by a time interval which was much too short to have produced such wide differences by the slow process of natural selection.

Remains of the earliest known teleost fishes are found in latest Jurassic and early Cretaceous strata. They were structurally very different from all known earlier fishes and possessed in full the distinguishing characteristics of the teleosts as they exist to-day. To say that no evidence of the gradual and slow evolution of the teleost fishes from older and very different ichthyic forms has ever been discovered is but to repeat what has been said of the sudden appearance of other highly organized forms.

A similar degree of suddenness marks the introduction of the placental mammalia, which occurred about the beginning of Tertiary time, as is shown by the righthand line under $F$ on the diagram. Those highly organized animals assumed faunal 
dominion of the earth, which the decadent dinosaurs had departed from. They came in a great diversity of forms, and their organization was little if any inferior in rank to that of the mammals now living of lower grade than the quadrumana. There has been found no evidence of their evolution from earlier forms by any slow process, not even from the previously existing non-placental mammals; and their species all became extinct at, or before, the close of the Eocene epoch. They were then replaced by the Miocene and Pliocene mammalia respectively, each fauna containing many strange and suddenly introduced forms, and each losing largely by extinction. Indeed, the history of the mammalia from the earliest Tertiary to the present time embraces a record of the rapid and varied evolution of the highest grades of animals, culminating in man. If it should ever be possible to trace the evolution of man from the lower animals it will doubtless be found that it has been accomplished, not by the slow process of natural selection, but by a series of sudden mutations.

In the foregoing remarks the terms rapid and sudden, referring to the introduction and extinction of the larger divisions of faunas and floras, are sometimes used in a comparative sense, and sometimes literally. The latter use of those terms, however, is more especially made when referring to species. If the introduction of families, orders and classes, and even of entire faunas and floras, was so effected as to give the appearance of suddenness, or even of rapidity, it necessarily follows that species, which are the recognized component units of those greater groups, were produced with actual suddenness.

The necessity for assuming the sudden origin of species being apparent, the first question that naturally arises is that of the manner of their origination. This must have been accomplished either by special creation, as was formerly believed, or by some natural genetic process of transformation. The time seems to have passed for giving any consideration to the former. proposition, and it only remains to consider some natural theory. While many expressions of belief have from time to time been made that species have originated suddenly by some natural process, the only clearly defined theory of this kind is the one proposed by Professor de Vries, of Amsterdam, under the name of the mutation theory. ${ }^{4}$ It is essentially as follows :

Species originate from other species through the ordinary function of reproduction, but they each originate suddenly and completely by one mutative act, and not by the slow cumulative variation of individuals. The beginning of the mutative process, which is due to some at present unknown natural determinate cause, is a rearrangement of the groups of component molecules of the protoplasmic contents of the germ cell. It occurs when the ovule containing that cell has, by the natural process of reproduction, been fertilized and is about to give origin to a new individual. If that molecular change occurs, the new individual thereby acquires changed structural characters and becomes an original representative of a new species. If no such molecular change occurs in the germ cell of a fertilized ovule, which is usually the case, the result is only that of ordinary reproduction. The new species thus produced by mutation is in immediate possession of clearly distinguishing and heritably transmissible characters; and it has no more tendency to hybridize with any member of the mother species than have other species. The characteristics and perpetuation of the mother species are in no way affected by

4 'Die Mutationstheorie,' von Hugo de Vries, Vols. J and 2, Leipzig, 1901, 1902. 
the mutative birth of one or more of her progeny.

Species thus produced by mutation are called elementary species. They differ distinctly but not widely from the mother species; wide differences result from the absence of intermediate elementary species. That is, the daughter species become mother species successively; a large part of the mutated, as well as of the ordinary, offspring soon perish in the struggle for existence, even with their own kindred, until wide differences between species of the same stock result. Species are destroyed in the struggle for existence, but that struggle plays no part in their origination.

That species have a real entity and, for the most part, an essentially unchanging existence, are facts of daily observation. They are born, and if they survive the struggle for existence to which they are immediately subjected, they usually have an extended duration; but they finally perish. The duration of a species has two periods, a mutative and a non-mutative period; the former being exceedingly short in comparison with the latter. So very much is the non-mutative period of all species in excess of the mutative, that all the species living in any large region at any given time are likely to be in the nonmutative condition. Furthermore, the process of mutation is so inconspicuous that it may easily escape detection. Attention is particularly called to the fact that mutation, using that term in its here adopted special sense, is as much a natural and normal process as is that of ordinary reproduction, with which function every case of mutation is concurrent. It is also in no way opposed to the great thesis of evolution, and is in full accord with Darwin's theory of common descent.

By referring to the three assumptions of the advocates of the theory of the origin of species by natural selection which are mentioned in the early part of this article, and comparing them with the immediately preceding statement of the mutation theory, it will be seen that this theory is directly opposed to them, but consistent with the facts which have been stated in preceding paragraphs. By further referring to those statements it will appear that in all the cases wherein the inapplicability of the origin of species by natural selection has been shown, the mutation theory is fully applicable. Indeed, the applicability of the latter theory is so apparent that only the following brief comments will be made in conclusion.

The assumption of an illimitably remote period for the beginning of life upon the earth, which the theory of the origin of species by natural selection requires, and which has been vigorously opposed by physicists as inconsistent with cosmical law, is shown by the mutation theory to be unnecessary. That question is, therefore, eliminated from all such discussions because the mutation theory presupposes a rapidity of evolution that would bring the beginning of life quite within the limits required by the physicists.

The comparative rapidity of introduction and dispersion upon the earth of certain genera, families, orders, classes and even of great faunas and floras, makes it necessary to infer the sudden origin of their elementary component units. Those facts and the inference mentioned are as consistent with the mutation theory as they are inconsistent with the theory of the origin of species by natural selection. Furthermore, the persistence of those faunal and floral groups through long periods of geological time with little change after they had become established, makes it necessary to infer the stable entity and 
heritability of species. Such an inference accords with the requirement of the mutation theory, but not with the theory which requires perpetual change in all species.

Certain groups of animals and plants have continued their existence without material change under very adverse conditions of physical environment which were seemingly more favorable for their existence than were those under which they originated. The theory of the origin of species by natural selection is at variance with such facts because it recognizes environing conditions as a constantly dominant factor in producing phylogenetic changes, on the one hand, and in preserving the integrity of faunal and floral types, on the other. The mutation theory recognizes the initiative action of an at present unknown determinate natural cause for phylogenetic changes. Environing physical conditions have doubtless been a potent cause in producing variations; and it has doubtless often had a controlling influence upon the destiny of faunas and floras; but such conditions have not been a direct factor in the origination of species.

Whatever criticisms may be made of the de Vriesian theory of mutation, the truth will remain that it accords with numerous important facts with which the theory of the origin of species by natural selection is quite inconsistent. Some theory which provides for the sudden, or rapid, origination of species is made necessary by a large array of geological facts, and the mutation theory more nearly meets that demand than does any other yet proposed.

Smithsonian Institution,

Charles A. White.

February 20, 1905.

\section{SCIENTIFIC BOOKS.}

Introduction à la Géométrie Générale. Par George Lechalas, Ingénieur 'en chef des ponts et chaussées. Paris, Gauthier-Villars. 1904. 'Pp. ix +58.
The Elements of Plane and Solid Analytical Geometry. By Albert L. Candy, Ph.D., assistant professor of mathematics in the University of Nebraska. B Boston, D. C. Heath \& Cq. 1904. Pp. $\mathrm{x}+248$.

The Elements of Analytic Geometry. Вy Percey F. Smith, Ph.D., professor of mathematics in the Sheffield Scientific School, Yale University, and ARThur S. GaLe, Ph.D., instructor in mathematics in Yale College. New York, Ginn \& Co. 1905. Pp. xii +424 .

An Introduction to Projective Geometry and Its Applications. By Arnold Emch, Ph.D., professor of graphics and mathematics in the University of Colorado. New York, John Wiley \& Sons. 1905. Pp. vii +267. Descriptive Geometry for Students of Engineering. Second edition. By JAMES A. MoYer, S.B., A.M., instructor in descriptive geometry in Harvard University. New York, John Wiley \& Sons. 1905. Pp. iv + 198.

The Elements of the Differential and Integral Calculus. By Donald F. Campbell, Ph.D., professor of mathematics, Armour Institute of Technology. New York, The Macmillan Company. 1904. Pp. $\mathrm{x}+364$.

Elements of the Differential and Integral Calculus. By William A. Granville, Ph.D., instructor in the Sheffield Scientific School, Yale University: New York, Ginn \& Co. 1904. Pp. xiv +463 .

The Boston Colloquium: Lectures in Mathematics. By Fidward B. Van Vleck, Henry S. White and Frederick S. Woods. New York, The Macmillan Company. (For the American Mathematical Society.) 1905. Pp. $\mathrm{x}+187$.

Except the last these works are all of them addressed to beginners in their respective subjects, and, except the first and last, they are designed for use as text-books in undergraduate study.

- The aim of Lechalas's splendid essay is orientation among the fundamental divisions of modern geometry conceived in full generality. Especially intended for such as have not formed a systematic conception of the Euclidean, Lobatchevskian and Riemannian 